\title{
Adherence assessment of eye drops in patients with glaucoma using 8 item Morisky Score: a cross sectional study
}

\author{
Avaliação da adesão aos colírios em pacientes com glaucoma \\ através da Escala de Morisky de 8 itens: um estudo transversal
}

Marina Viegas Moura Rezende Ribeiro1, Luiz Eduardo Feliciano Ribeiro², Êurica Adélia Nogueira Ribeiro³, Caio Vítor Ferreira $^{4}$, Fabiano Timbó Barbosa ${ }^{3}$

\begin{abstract}
Objective: To determine adherence to glaucoma eye drops in patients from Glaucoma Project (Ministry of Health) by Morisky scale of 8 items. Methods: We conducted a cross-sectional study through a questionnaire applied to 237 patients diagnosed with glaucoma regularly enrolled in the Glaucoma Project at Institutode Olhos de Maceio, adapting the Morisky scale, already validated in Portuguese, for eyedrops. The variables were adherence to antiglaucoma eyedrops, age, sex, race, glaucoma diagnosis time, eyedrops number used, systemic diseases, education, subjective vision (categorized in bad, reasonable or good) and the factors correlated with poor adherence. Statistical analysis between variables was performed with the statistical test Chi-square test for categorical variables and test MannWhitney test for continuous outcomes, considering a 5\% significance level. Results: The rate of adherence to the glaucoma drops was $54 \%$. The age and number of drops ( $p=0.02$ and 0,03 respectively), and quality of vision $(p<0,001)$ were statistically significant for the inappropriate use of the therapy and the most common reason both adherent group as the non-adherent was forgetfulness $(23 \%$ and 76,15\% respectively). Conclusion: Using the Morisky scale adapted to antiglaucoma eyedrops the adherence was $54 \%$.

Keywords: Medication adherence/statistics \& numerical data; Patient compliance; Treatment refusal; Ophthalmic solutions/therapeutic use; Glaucoma/drug therapy
\end{abstract}

\section{RESUMO}

Objetivo: Determinar a adesão aos colírios antiglaucomatosos em pacientes do Projeto Glaucoma (Ministério da Saúde) por meio da escala de Morisky de 8 itens. Métodos: Foi realizado um estudo transversal por meio de questionário aplicado a 237 pacientes diagnosticados com glaucoma inscritos regularmente no Projeto Glaucoma do Instituto de Olhos de Maceió, adaptando a escala de Morisky já validada em português para colírios. As variáveis foram a adesão aos colírios antiglaucomatosos, idade, sexo, raça, tempo de diagnóstico do glaucoma, número de colírios utilizados, doenças sistêmicas, escolaridade, perfil de visão (ruim, razoável ou boa) e os fatores correlacionados com a adesão. A análise estatística entre as variáveis foi realizada com os testes estatísticos do Quiquadrado para as variáveis categóricas e Teste U de Mann-Whitney para as contínuas, considerando um nível de significância de $5 \%$. Resultados: A adesão aos colírios foi de $54 \%$. A idade e o número de colírios ( $\mathrm{p}=0,02$ e 0,03 respectivamente) foram estatisticamente relevantes, assim como a qualidade de visão também foi $(\mathrm{p}<0,001)$ para o não uso adequado do tratamento. $\mathrm{O}$ motivo mais comum tanto no grupo de aderentes como no de não aderentes foi o esquecimento ( $23 \%$ e $76,15 \%$ respectivamente). Conclusão: Utilizando a escala de Morisky adaptada para colírios antiglaucomatosos a adesão aos colírios foi de $54 \%$.

Descritores: Adesão ao tratamento/estatística \& dados numéricos; Cooperação do paciente; Recusa do paciente ao tratamento; Soluções oftálmicas/uso terapêutico; Glaucoma/quimioterapia

\footnotetext{
${ }^{1}$ Universidade Tiradentes - Maceió (AL), Brasil;

${ }^{2}$ Instituto de Olhos de Maceió - Maceió (AL), Brasil;

${ }^{3}$ Universidade Federal de Alagoas - Maceió (AL), Brasil;

${ }^{4}$ Curso Acadêmico de Medicina, Universidade Tiradentes - Maceió (AL), Brasil.

Work done at the Eyes Institute of Goiânia.

The authors declare no conflicts of interests.

Received for publication 01/07/2016 - Accepted for publication 26/09/2016.
} 


\section{INTRODUCTION}

$\mathbf{G}$ laucoma is a leading cause of blindness in adults, leading in black and latinos ${ }^{1}$. Because glaucoma is an initially asymptomatic disease ${ }^{2}$, low adhesion to antiglaucomatous eyedrops ranges from 30 to $80 \%$ in the literature ${ }^{3}$. It is known that inappropriate use of eyedrops is related to the bad control of intraocular pressure and thus to optic neuropathy leading to vision loss. ${ }^{4}$ Because uncontrolled intraocular pressure alone does not indicate a poor adhesion, nor a normal pressure measurement indicates good adhesion 5 .

There are several reasons in the literature which lead to non-adhesion of patients with glaucoma to eyedrops that can be cited as a cause leading the patient to not use their eye drops properly, such as the lack of knowledge about the disease, forgetfulness, lack of confidence in the doctor, the side effects of eyedrops, and even the fact that the patient does not understand well the disease nor believes that it causes blindness's

Currently there are several instruments to evaluate adhesion to medicines in cronic diseases ${ }^{6}$. The Morisky Accession scale is one of the most validated questionnaires used to assess the adhesion to medication that has been used not only in ophthalmology, but mainly in glaucoma, ${ }^{3,7-12}$ as well as other chronic diseases such as diabetes, osteoporosis, hypertension, epilepsy, transplants in use of immunosuppressants, among other chronic diseases. ${ }^{13-18}$ This scale of 8 items (Morisky Medication Adhesion Score-MMAS-8) has already been validated in Portuguese for $\mathrm{HAS}^{19}$.

The overall objective of this study is to evaluate adhesion to eyedrops in patients with glaucoma, since there are no studies using the scale of Morisky for eyedrops in Brazil, adapting this scale in Portuguese for use with eyedrops.

\section{Methods}

We conducted a cross-sectional study through response to a form applied by a trained interviewer to patients in the waiting room of Projeto Glaucoma do Ministério da Saúde, at Instituto de Olhos de Maceió, in Alagoas, during the period from May 17 to May 24, 2016. This research was approved by the Ethics Committee CAAE 55315916.1.0000.5013.

The patients included were those who were properly registered in the Glaucoma project, receiving eyedrops periodically at no cost. The exclusion criteria were patients who had been missing their appointments for the last 3 months. Patients who have expressed interest in participating in the research have signed an informed consent (TCLE).

\section{Questionnaire and variables}

Primary variables were adhesion to medication, the number of eyedrops used and the time of glaucoma, secondary variables were the reasons of low adhesion, the subjective quality of vision, and chronic diseases. And tertiary variables were age, sex, color, and education. The patient data was collected with a questionnaire divided into three parts: first questions about the patient demographics, time of diagnosis of glaucoma, number of eyedrops used, systemic diseases, education, and how the patient considered their vision, that is, vision profile (bad, fair, or good). The second part of the questionnaire presented the Morisky scale that consists of 8 questions (Morisky Medication Adhesion 8 items-
MMAS-8) with dichotomous responses (yes/no), and the last with 5 answers that are: "never, hardly ever, sometimes often and always":

\section{MMAS-8}

1. Do you sometimes forget instilling your eyedrops? (1) Yes (2) No

2. In the last two weeks, was there some day you forgot instilling your eyedrops? (1) Yes (2) No

3. Have you ever stopped instilling your eyedrops because you were feeling worse without telling your doctor? (1) Yes (2) No

4. When you travel or leave home, do you sometimes forget to take your eyedrops? (1) Yes (2) No

5. Did you instill your eyedrops yesterday? (1) Yes (2) No

6. When you feel better, when I feel that your eye problem is controlled, do you sometimes avoid instilling your eyedrops? (1) Yes (2) No

7. Have you ever felt bothered by forgetting any dose, forgetting to instill your eyedrops? (1) Yes (2) No

8. How often do you forget instilling these eyedrops?

(1) Never (2) Hardly ever (3) Sometimes (4) Frequently (5) Always

Each negative response was worth 1 point (questions 1 to 4), question 5 is reversed, so if the answer was affirmative it would be worth 1 point, and questions 6 and 7 would be like the first four. The last question would be worth 1.0 to zero, being the count every 0.25 . If the person scored between 0 and 5.75, they were considered non-adherent, if scored from 6 to 8 they would be classified as adherent. ${ }^{12}$ This Morisky scale already validated in Portuguese ${ }^{19}$ was adapted for the use of eyedrops. In the first step, the questionnaire was tested in 20 patients to test the comprehension of the scale by the general population; the questions were understood by all individuals and modifications were not necessary.

Afterwards, a single question was created to assess the correlation between the result of the questionnaire adapted to eyedrops of Morisky and the direct response of the patient to this extra question, due to the absence of a validated instrument in Portuguese to serve as a reference to verify that the result of this adapted version for eyedrops of Morisky scale was accurate scale for assessing the adhesion (Spearman's correlation: 0.7, $\mathrm{p}=0.02$ ).

The number of correlation was of 40 patients, enough to assess the internal consistency of the questionnaire by calculating Cronbach's alpha, which was 0.74 . In the third part of the questionnaire, patients answered to the question: "what are the reasons to make you stop instilling your drops?" This question presented multiple-choice answers that are the factors that may be associated with low adhesion: (a) I believe that the glaucoma does not cause vision loss, (b) I can't believe these eyedrops are effective, (c) I don't have much knowledge about this disease, (d) forgetfulness, (e) difficulties to understand how to use the eyedrops, $(f)$ due to the side effects, $(g)$ difficulties with the medication time, (h) lack of confidence in my doctor, (i) very stressful life. In this section, the patient could choose more than one option. ${ }^{3}$

This was accomplished in a predetermined time of 10 minutes, and was followed by a member of the research, trained to answer the patients' questions.

\section{Calculation of sample size}

The questionnaire was applied to 237 individuals, considering the percentage of adhesion to studies using Morisky scale in the original study was $16 \%$, with a significance level of $5 \%$ and confidence interval of $95 \%$. Forty patients were used to 
verify the correlation, considering a correlation of 0.3 , a significance level of $5 \%$ and a statistical power of $80 \%$. The number of patients used in the correlation was considered enough to calculate the alpha of Crombach; measured by the number of items of the questionnaire by non-parametric approach to calculate the size of the sample based on questionnaires ${ }^{20}$. All calculations were performed using Stata software version 13 (Stata Corporation, College Station, TX, USA).

\section{Description of variables}

The description of the variables is evaluated by descriptive statistics, as follows: average and standard deviation will be held for continuous variables and frequencies and percentages for categorical.

\section{Statistical analysis}

The data was collected in a standardized form, and stored in an electronic datasheet (Microsoft Excel®). Redmond, WA, USA). In this, each line corresponds to a data collection form, and each column to the data collected. The test of Shapiro-Wilk normality was carried out for continuous variables, and then the Mann-Whitney test was chosen for calculation of $\mathrm{p}$; and for categorical variables we used the Chi-square test for calculation of $p$, which is statistically significant when less than 0.05 .

\section{Results}

Of 237 patients, $128(54 \%)$ were adherent to the glaucoma eyedrops, and 109 (46\%) were non-adherent (with scores in the Morisky scale of less than 6 points). Patients were mostly from Maceió, being 165 (69.62\%) from the total, and the rest was from other cities in the countryside of Alagoas.

The main findings between the groups adherent and nonadherent are summarized in table 1 . Of the total patients, the average age of all patients was $60.13 \pm 13.06$. The Group nonadherent showed more young patients than the Group adherent $(57.48 \pm 62.53 \pm 11.70$ and 14.00 respectively $)(p=0.02)$. Of all patients interviewed, 91 were males $(38.40 \%)$ and 146 were females $(61.60 \%)$.

The time of diagnosis of glaucoma of all patients was mainly in the range of less than 5 years $(112 / 230$ or $48.70 \%)$. The time of

Table 1

Patient profile

\begin{tabular}{|c|c|c|c|c|}
\hline & & $\begin{array}{c}\text { Adherent (\%) } \\
\text { n=128 }\end{array}$ & $\begin{array}{c}\text { Non-adherent }(\%) \\
n=109\end{array}$ & p-Value \\
\hline \multirow[t]{2}{*}{ Sex } & & & & 0.72 \\
\hline & Female & 60.16 & 63.30 & \\
\hline \multirow[t]{4}{*}{ Education } & & & & 0.07 \\
\hline & Just literacy & 10.32 & 14.29 & \\
\hline & High school (complete or not) & 19.84 & 27.62 & \\
\hline & Graduation (complete or not) & 6.35 & 13.33 & \\
\hline \multirow[t]{4}{*}{ Ethnicity } & & & & 0.73 \\
\hline & White & 37.17 & 35.9 & \\
\hline & Black & 18.58 & 17.98 & \\
\hline & Brown & 44.25 & 44.94 & \\
\hline \multirow{2}{*}{ Time of glaucoma } & up to 5 years & 52.03 & 44.86 & \\
\hline & more than 20 years & 5.69 & 2.80 & \\
\hline \multirow[t]{5}{*}{ Number of eyedrop } & & & & 0.03 \\
\hline & 1 & 32.28 & 20.56 & \\
\hline & 2 & 19.69 & 20.56 & \\
\hline & 3 & 42.52 & 41.12 & \\
\hline & 4 or more & 5.51 & 17.76 & \\
\hline
\end{tabular}

diagnosis of glaucoma was prevalent in the range of up to 5 years, being 64/123 (52.03\%) in the Group adherent, and 48/107 $(44.86 \%)$ in the group non-adherent $(\mathrm{p}=0.06)$. The number of eyedrops used follows table 1.

The number of chronic diseases in all patients was 278 , the most cited disease was hypertension (95 reports, $34.17 \%$ ). In the group of non-members there were 122 reports of chronic diseases, while in the adherent group there were 156 reports of chronic conditions in total. HAS was also mentioned in $32.79 \%$ of adherent and $35.26 \%$ in the group non-adherent $(p=0.71)$.

Regarding the subjective account of quality of vision in the total of patients with glaucoma, $45(19.74 \%)$ reported that the vision was good, $0.125(54.82 \%)$ that was "reasonable" and 55 $(24.12 \%)$ that was "bad". In the group non-adherent, $21.36 \%$ 
said that the vision was "bad", $60.18 \%$ was "reasonable" and $18.46 \%$ reported being "good"; while in the Group adherent, $23.20 \%$ reported that the vision was "good", $49.60 \%$ was "reasonable" and $26.40 \%$ that was "bad". There was a statistically significant difference between patients adherent and nonadherent, where the report of "good" vision was greater in adherent patients, and the report of "bad" vision was also higher in this group $(\mathrm{p}<0.001)$.
Overall, the main reason reported in the total of 237 patients preventing the patient to use eyedrops was forgetting, with a total of 112 patients; followed by: 17 patients who reported the reason "very stressful life", 12 who reported problems with the time of medication, 11 who reported it was due to side effects, 2 which mentioned lack of knowledge about the disease, 1 who did not believe that the eyedrops were effective, and 1 who did not believe that glaucoma caused vision loss. (Table 2)

Table 2

Reasons for improper use of eyedrops

\begin{tabular}{lcc}
\hline & Adherent (\%) & Non-adherent (\%) \\
\hline I believe that the glaucoma does not cause loss of vision & 0,00 & 0,92 \\
I can't believe these eyedrops are effective & 0,00 & 0,92 \\
I don't have much knowledge about this disease & 0,00 & 1,83 \\
Forgetfulness & 23,00 & 76,15 \\
Difficulties to understand how to administer eyedrops & 0,00 & 0,00 \\
Due to side effects & 1,60 & 8,26 \\
Difficulty with the time of medication & 0,00 & 11,01 \\
Lack of confidence in my doctor & 0,00 & 0,00 \\
Very stressful life & 4,70 & 10,09 \\
\hline
\end{tabular}

\section{Reasons for non-adhesion to glaucoma eyedrops in adherent patients}

Among the reasons for non-adhesion, the three main factors reported in the group of patients who were adherent, 29/ 128 responses $(23 \%)$ reported the reason "forgetfulness" as the main cause. Other 6 (4.70\%) reported "very stressful life," and two of them $(1.60 \%)$ reported that the reason for not using the eyedrops sometimes was side effects.

\section{Reasons for non-adhesion to glaucoma eyedrops in adherent patients}

The three main reasons for non-adhesion in the group of patients who were non-adherent (those who scored in Morisky scale from 0 to 5.75$), 83 / 109$ responses $(76.15 \%)$ reported the reason "forgetfulness" as the main cause. Other $12(11.01 \%)$ reported "difficulty with time", and 11 of them $(10.08 \%)$ reported that the reason not to use the eyedrops sometimes was "stressful life".

\section{DisCUSSION}

Poor adherence to treatment with antiglaucomatous eyedrops is a problem regarding the prognosis of the disease, and ranges from $5 \%$ to $80 \%$ according to a meta-analysis conducted in 2005, consistent with the adhesion rate found in this study which was $46 \%$. $^{7}$ These rates vary widely due to the methods used to assess adhesion in patients with glaucoma ${ }^{21}$. In Brazil, no study to evaluate adhesion to eyedrops used the validated Morisky scale of 8 items, but other questionnaires or structured interviews. ${ }^{22-24}$

The Morisky scale is a validated scale which has been used in various types of chronic diseases, being one of the principal for this purpose. It has the advantage of being able to be adapted to various diseases and various types of medications, with good reproducibility. And in ophthalmology it has also been the most commonly used ${ }^{2,3,14}$.

Regarding the demographic characteristics of the patients, it was observed that the patients in the group non-adherent were younger than in the group adherent. Age was a controversial factor in the literature as a risk factor for low adhesion, since a recent systematic review showed that most of the studies did not present significant differences with age ${ }^{21}$. However a recent study using the Morisky scale also showed that the group non-adherent was significantly younger than the adherent ${ }^{3}$.

Regarding sex, color, and education, and number of chronic diseases, these data was not statistically significant, which was also compatible with the literature. ${ }^{3,21}$

The number of eyedrops in our study was statistically significant between patients in the groups adherent and nonadherent, since, for example, it was observed that in the group adherent more patients used only 1 eyedrop (32.28\%) compared to $20.56 \%$ of non-adherent. It is believed that a better adhesion occurs in patients who only use eyedrops because it would be easier to remember using less medication ${ }^{21}$. Therefore, we attribute the fact that patients who used 4 eyedrops were far fewer adherent because it is much easier to forget the doses with a large number of eyedrops, and also because of the side effects that can increase the greater the number of medications.

The time of diagnosis of glaucoma, that in both groups was more common in the range of less than 5 years of disease, was not statistically significant, consistent with the literature which also proved to be a relevant factor for low adhesion ${ }^{3}$.

When evaluating the quality of subjective vision among patients, it was observed that the group adherent reported a better visual acuity than the group non-adherent, and also a higher percentage of patients who reported that the visual acuity was "bad" in this group. Newman-Casey et al.(3) assessed the subjective acuity, but the $\mathrm{p}$ value $(\mathrm{p}=0.8)$ was not significant. A 
recent systematic review noted that the articles did not assess the subjective vision, but the loss of the visual field, which was also not statistically relevant. However, we could assign this finding to the fact that the adherent patients have better vision because they use their medications more correctly, and the fact that the group adherent also has a higher percentage of bad vision than non-adherent, and the possibility that this group uses more eyedrops due to be losing more vision, when compared to non-adherent.

It is known that there are several factors or reasons that are proven in the literature as a cause of low adhesion to glaucoma eyedrops. ${ }^{3}$ In this study, it was observed that in both groups adherent and non-adherent the main reason not to use eyedrops properly was the "forgetfulness" (23\% and $76.15 \%$ respectively). It seems to be easier to say you forgot the eyedrops than to discuss other points that would be more difficult to the patient, because it could generate a conflict with the doctor.

An important reason for non-adhesion to medication has been the cost, except that in this study the eyedrops were distributed for free in this Government Program (Projeto Glaucoma) which eliminates this factor ${ }^{3}$.

In a recent study of 2015, the authors found a similar rate of forgetfulness in the two groups of $23 \%$ in adherents, and $62 \%$ in non-adherent. ${ }^{3}$ This result was also consistent with several studies showing that forgetfulness was the main factor for non-adhesion, including the most recent systematic review, this factor was the only one who had significant relevance along with the problem with the time of medication in low adhesion. ${ }^{3,21,24}$

One way of trying to avoid forgetfulness by patients in using eyedrops would be using an alarm to remind them, or automated text notes to try and reduce this risk factor. ${ }^{25,26}$

The other two most mentioned reasons in the group non-adherent were the difficulty with the time of eyedrops $(11.01 \%)$ and stressful life $(10.08 \%)$. The difficulty with time was, as mentioned above, the most relevant factor found among the authors, ${ }^{20}$ however at a higher percentage, for example, Newman-Casey et al. found that $47 \%$ of non-adherent reported difficulty with the time of eyedrops, and stressful life was reported by $43 \%$ of patients 3 .

In the group adherents, only those with moderate adhesion presented a reason, since those with scores of 8 , i.e., with full adhesion, never forgot their medication. Among them, in addition to forgetfulness that was the main reason, the other two most mentioned reasons were stressful life $(4.70 \%)$ and side effects of the eyedrops $(1.60 \%)$. The side effects of the eyedrops are mentioned as the cause of no usage. Taylor et al. found that almost $10 \%$ of their patients did not use the eyedrops because of the side effects. ${ }^{27}$ Stressful life was mentioned by the adherent in the study of Newman-Casey et al., with a rate of $25 \% .^{3}$

The implications for further research are that adhesion to eyedrops evaluated by the Morisky scale adapted to Portuguese for antiglaucomatous eyedrops, and they were compatible with the literature..$^{2,3,5,7} \mathrm{New}$ studies in Brazil can be carried out using this instrument already validated, even in other eye diseases other than glaucoma.

Counseling strategies should also be created for these patients, so that they and their caregivers are educated to understand the importance of using eyedrops first, as this can also reduce forgetfulness, and also strengthen measures such as alarms to remind the patient of their medicine.

\section{Conclusion}

What we can learn from this study is that there was low adhesion of almost half of the patients, and that it was well reviewed with Morisky scale in Portuguese adapted for eyedrops. The large number of eyedrops and mainly reasons such as forgetfulness and difficulty with the time of medication are factors that can be minimized to improve adhesion to eyedrops in patients with glaucoma. The doctor should try to reduce the number of eyedrops prescribed whenever possible depending on each patient's case.

The importance of this research is that ophthalmologists may guide their patients to the best use of their medications in an attempt to reduce visual loss for glaucoma, which in part can be caused by non-adhesion of patients to eyedrops.

\section{ReFERENCES}

1. Quigley HA, Broman AT. The number of people with glaucoma worldwide in 2010 and 2020. Br J Ophthalmol. 2006;90(3):262-7.

2. Cate H, Bhattacharya D, Clark A Holland R, Broadway DC.. A comparison of measures used to describe adherence to glaucoma medication in a randomised controlled trial. Clinical Trials. 2015;12(6): 608-17.

3. Newman-Casey, PA, Blachley T, Farris K, Heisler M, Resnicow K, Lee PP. The most common barriers to glaucoma medication adherence: a cross-sectional survey. Ophthalmology. 2015:122(7): 1308-16.

4. Lee PP, Walt JW, Rosenblatt LC, Siegartel LR, Stern LS. Association between intraocular pressure variation and glaucoma progression: data from a United States chart review. Am J Ophthalmol. 2007;144(6):901-7

5. Cate H, Broadway DC. Association between intraocular pressure and adherence: is there one. Eye (London). 2011;25(9):1238-9.

6. Pérez-Escamilla B, Franco-Trigo L, Moullin JC, Martínez-Martínez F, García-Corpas JP. Identification of validated questionnaires to measure adherence to pharmacological antihypertensive treatments. Patient Prefer Adherence. 2015;9:569-78.

7. Olthoff, Christine MG, Schouten JS, van de Borne BW, Webers CA. Noncompliance with ocular hypotensive treatment in patients with glaucoma or ocular hypertension: an evidence-based review. Ophthalmology . 2005;112(6): 953-61.

8. Schwartz, GF, Quigley HA. Adherence and persistence with glaucoma therapy. Surv Ophthalmol. 2008; 53(6): S57-S68.

9. Weiss GA, Goldich Y, Bartov E, Burgansky-Eliash Z. Compliance with eye care in glaucoma patients with comorbid depression. Israel Med Assoc J. 2011; 13(12):730-4.

10. Sleath B, Blalock SJ, Robin A, Hartnett ME, Covert D, DeVellis B, Giangiacomo A. Development of an instrument to measure glaucoma medication self-efficacy and outcome expectations. Eye (London). 2010; 24(4):624-31.

11. Lynne B, Craig J, Little J. Compliance to Glaucoma Medication and its effect on Treatment regime. Clin Exp Ophthalmol. 2014;42(.Suppl 1): 74-129.

12. Morisky DE, Ang A, Krousel-Wood M, Ward HJ. Predictive validity of a medication adherence measure in an outpatient setting. J Clin Hypertens (Greenwich). 2008;10(5):348-54.

13. Souza RA. Qualidade de vida relacionada à saúde, controle glicêmico e seus determinantes em pacientes com diabetes mellitus tipo 2 [tese]. Curitiba: Universidade Federal do Paraná; 2008. 
14. Oliveira-Filho AD, Barreto-Filho JA, Neves SJ, Lyra Junior DP Association between the 8-item Morisky Medication Adherence Scale (MMAS-8) and blood pressure control. Arq Bras Cardiol. 2012; 99(1): 649-58.

15. Gutiérrez-Angulo ML, Lopetegi-Uranga P, Sánchez-Martín I, Garaigordobil-Landazabal M. Cumplimiento terapêutico en pacientes com hipertensión arterial y diabetes mellitus tipo 2 . Rev Calid Asist. 2012; 27(2):72-7.

16. Butler JA, Peveler RC, Roderick P, Horne R, Mason JC. Measuring compliance with drug regimens after renal transplantation: comparison of self-report and clinician rating with electronic monitoring. Transplantation. 2004; 77(5): 786-9.

17. Nakhutina L, Gonzalez JS, Margolis SA, Spada A, Grant A. Adherence to antiepileptic drugs and beliefs about medication among predominantly ethnic minority patients with epilepsy. Epilepsy Behav. 2011; 22(3):584-6.

18. Remondi FA, Cabrera MA, Souza RK. Não adesão ao tratamento medicamentoso contínuo: prevalência e determinantes em adultos de 40 anos e mais. Non-adherence to continuous treatment and associated factors: prevalence and determinants. Cad Saúde Pública. 2014; 30(1): 126-36

19. de Oliveira-Filho AD, Morisky DE, Neves SJ, Costa FA, de Lyra DP Jr. The 8-item Morisky Medication Adherence Scale: validation of a Brazilian-Portuguese version in hypertensive adults. Res Social Adm Pharm. 2014; 10(3): 554-61.

20. Couto Jr EB. Abordagem não-paramétrica para cálculo do tamanho de amostra com base em questionários ou escalas de avaliação na área de saúde [tese]. São Paulo: Universidade de São Paulo; 2009

21. De Castro AN, Mesquita WA. Noncompliance with drug therapy of glaucoma: a review about intervening factors. Braz J Pharm Sci. 2009; 45(3):453-9.
22. De Castro AN, Mesquita WA. Não-adesão à terapêutica medicamentosa do glaucoma. Arq Bras Oftalmol. 2008;71(2): 207-14.

23. Silva LR, Paula JS, Rocha EM, Rodrigues ML. Fatores relacionados à fidelidade ao tratamento do glaucoma: opiniões de pacientes de um hospital universitário. Arq Bras Oftalmol. 2010; 73(2): 116-9.

24. Buscacio ES, Colombini GN. Estudo sobre os fatores relacionados a interrupção do tratamento do glaucoma. Rev Bras Oftalmol. 2011;70(6):371-7.

25. Frick PA, Lavreys L, Mandaliya K, Kreiss JK. Impact of an alarm device on medication compliance in women in Mombasa, Kenya. Int J STD AIDS 2001;12(5):329-33.

26. Boland MV, Chang DS, Frazier T, Plyler R, Jefferys JL, Friedman DS. Automated telecommunication-based reminders and adherence with once daily glaucoma medication dosing: the automated dosing reminders tudy. JAMA Ophthalmol.2014;132(7):845-50

27. Taylor SA, Galbraith SM, Mills RP. Mills. Causes of non-compliance with drugr egimens in glaucoma patients: a qualitative study. J Ocul Pharmacol Ther. 2002;18(5):401-9.

\section{Corresponding author:}

Marina Moura Rezende

Av.Comendador Palmeira, 100, Farol - Maceió, AL - Brasil

Phone: 55 (82) 2126-3600

Email: dra.marinaribeiro@gmail.com 